\title{
Functional significance of intramandibular bending in Poeciliid fishes
}

\author{
Alice Gibb • Lara A. Ferry-Graham • \\ L. Patricia Hernandez • Rebecca Romansco • \\ Jessica Blanton
}

Received: 18 October 2007 / Accepted: 19 May 2008 / Published online: 5 July 2008

(C) Springer Science + Business Media B.V. 2008

\begin{abstract}
Substrate-feeding teleosts show multiple, independent evolutionary acquisitions of intramandibular bending (bending within the lower jaw) — a behavior that likely enhances performance when feeding on attached or encrusting food items. However, intramandibular bending has only been quantified for marine teleosts. Here, we examine substrate feeding in eight species from the order Cyprinodontiformes and quantify movements produced by the anterior jaws of four target species selected from the family Poeciliidae to represent a variety of trophic strategies. Intramandibular bending, defined here as bending between the dentary and angular-articular bones of the lower jaw, is not present in some poeciliids (i.e. Gambusia affinis), nor is it present in outgroup cyprinodontiforms (i.e. Fundulus rubrifrons). However, intramandibular bending is
\end{abstract}

A. Gibb $(\bowtie) \cdot$ R. Romansco $\cdot$ J. Blanton

Department of Biological Sciences,

Northern Arizona University,

Flagstaff, AZ 86011-5640, USA

e-mail: Alice.Gibb@nau.edu

L. A. Ferry-Graham

Moss Landing Marine Laboratories,

California State University,

8272 Moss Landing Rd,

Moss Landing, CA 95039, USA

L. P. Hernandez

Department of Biological Sciences,

The George Washington University,

Washington, DC 20052, USA present in certain poeciliids (i.e. Poecilia sphenops), and can exceed $90^{\circ}$. Such jaw bending enables the production of a gape angle that approaches $120^{\circ}$, which likely allows the fish to maximize contact between the toothed tips of the jaws and the substrate during the bite. Intramandibular bending in poeciliid species is associated with specific trophic shifts: the greater the intramandibular bending in a given species, the more attached algae (periphyton) reported in its diet. This result supports the hypothesis that intramandibular bending enhances performance when feeding on encrusting food items. We predict that additional examples of functional convergence are likely to be documented in freshwater teleosts as more herbivorous species are examined, and we propose that intramandibular bending represents an excellent model system in which to examine the functional processes that underlie convergent evolution.

Keywords Convergent evolution - Algae scraping · Substrate feeding · Trophic evolution · Herbivory · Poeciliidae · Cyprinodontiformes · Oral jaws · Grazing

\section{Introduction}

Although suction is the dominant feeding mechanism among teleosts (Lauder 1985), members of many large and successful teleost lineages have become specialized for feeding on encrusting or epiphytic material (hereafter, encrusting food items). In these lineages, 
suction may not be required to draw food into the mouth; fish that feed on encrusting food items typically apply the lower jaw directly to the substrate to facilitate biting or scraping to remove attached animals or plants. In some instances, fish even remove the entire upper layer of the substrate itself - as when feeding on corals or sponges (Bellwood 1994).

Species that feed on encrusting or attached food items in this manner often demonstrate intramandibular "bending", which is facilitated by an additional joint located within the mandible, or lower jaw (Fig. 1). Teleost groups that demonstrate intramandibular bending include: angelfishes (Pomacanthidae; Konow and Bellwood 2005); surgeonfishes (Acanthuridae; Purcell and Bellwood 1993); parrotfishes (Scaridae; Bellwood 1994; Streelman et al. 2002); blennies (Blennidae; Springer 1988; Konow and Bellwood 2005); sea chubs (Kyphosidae; Vial and Ojeda 1990; Vial and Ojeda 1992); and kissing gourami (Helostomatidae; Liem 1967; Walsh et al. 2007). The intramandibular joint possesses a unique morphology in each family; however, it is typically located between the dentary and the angular-articular bones within the mandible. This presents a striking example of functional convergence as the intramandibular joint has evolved independently from an ancestral, unified mandible multiple times, presumably in response to the functional challenge of removing encrusting material from the substrate (Konow et al. 2008).

Intramandibular bending is well documented in many marine teleosts, but has only been described for one freshwater species, the kissing gourami. However, grazing herbivory has evolved independently many times within freshwater teletosts (Matthews 1998) and is particularly important to certain species in the family Poeciliidae (Hunt 1953; Zaret and Rand 1971). The remarkable incidence of functional convergence among marine species that feed on encrusting food items suggests that intramandibular bending provides a distinct performance advantage when grazing on foods that are attached to the substrate (Konow et al. 2008). Thus, we predict that intramandibular bending is present in other freshwater grazers, but remains undescribed.

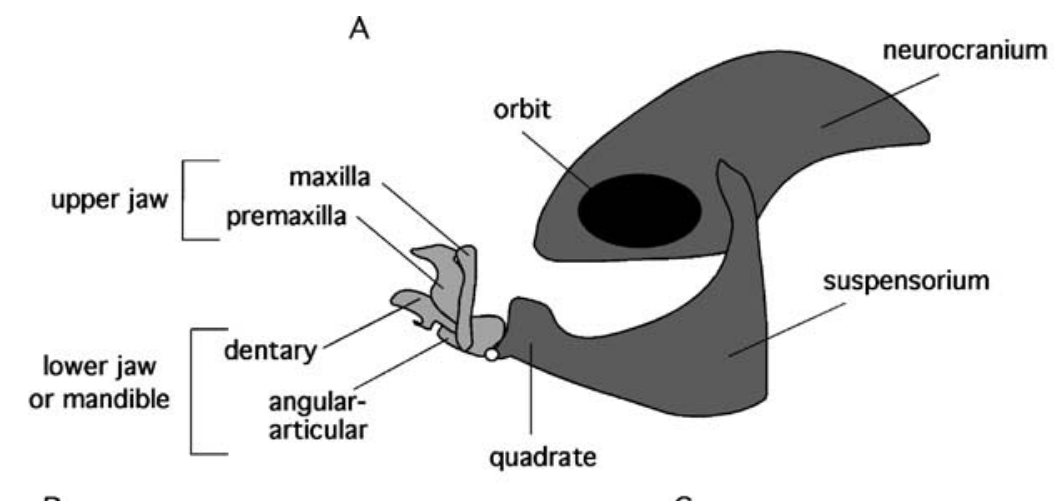

B

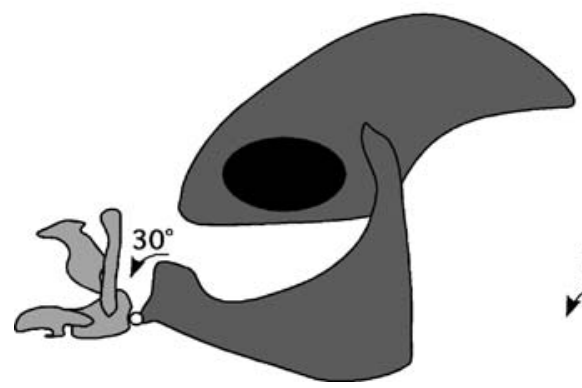

Fig. 1 Schematic illustration of aspects of the skull and jaws of Poecilia sphenops. Neurocranium and suspensorial elements illustrated in dark grey; elements of the upper and lower jaws illustrated in light grey. a Jaws closed (upper jaw retracted and lower jaw elevated) prior to feeding. b Jaws opened by means of upper jaw protrusion and $\sim 30^{\circ}$ of rotation of the lower jaw

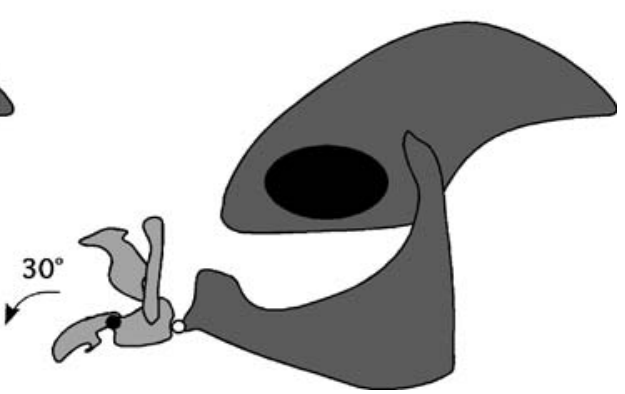

(or mandible) about its articulation with the quadrate bone of the suspensorium (small white circle). c Jaws opened as in $\mathbf{b}$, but with the addition of $\sim 30^{\circ}$ of rotation of the dentary about the intramandibular joint (small black circle). Note that the gape produced with intramandibular bending (c) is larger than that produced without intramandibular bending (b) 
Here, we examine eight species chosen to represent a phylogenetic "cross-section" through the predominantly freshwater order Cyprinodontiformes (Fig. 2) to determine (1) if these species are willing to feed on encrusting material and (2) if intramandibular bending is produced during feeding. Subsequently, we conduct a quantitative study of the movements produced during substrate feeding in four representatives of the Poeciliidae (Cyprinodontiformes) - a large family in which all members reproduce by internal fertilization and give birth to live young. We choose the Poeciliidae because they demonstrate diversity in foraging habits: this group contains grazing herbivores, omnivores, carnivores, and even piscivores (Meffe and Snelson 1989). The four poeciliid species examined here (hereafter, target species) were chosen to represent a broad range of feeding strategies, different phylogenetic positions within the family (Fig. 2), and because preliminary trials suggested that they might produce intramandibular bending while feeding.

Thus, we describe behavioral responses to attached food items in eight cyprinodontiform species: Kryptolebias marmoratus (mangrove killifish, formerly Rivulus marmoratus, Rivulidae), Fundulus rubrifrons (red-finned topminnow, Fundulidae), Jordanella floridae (flagfish, Cyprinodontidae), Belonesox belizanus (pike killifish, Poeciliidae), Gambusia affinis (mosquitofish, Poeciliidae), Heterandria formosa (least killifish, Poeciliidae), Xiphophorus helleri (green swordtail, Poeciliidae) and Poecilia sphenops (black molly, Poeciliidae). In our target poeciliid species (Gambusia, Heterandria, Xiphophorus and Poecilia), we also examine the head and jaw movements associated with feeding on material attached to the substrate to determine if there are kinematic differences among these taxa. For all species, we combine observations of feeding behavior in the laboratory with diet information from the literature to assess the evolutionary hypothesis that a diet dominated by algae or other encrusting material is associated with intramandibular bending. Specifically, we predict that species with significant amounts of attached algae (periphyton) in the diet will produce intramandibular bending, while species with a diet comprised of more elusive prey items (e.g. mobile invertebrates) will not produce intramandibular bending.

\section{Methods}

Species and husbandry

Individuals representing five poeciliid species (Gambusia affinis, Belonesox belizanus, Heterandria formosa, Xiphophorus helleri, and Poecilia sphenops) and three "outgroup" families (Jordanella floridae, Cyprinodontidae; Fundulus rubrifrons, Fundulidae;
Fig. 2 Simplified cladogram illustrating hypothesized relationships among cyprinodontiform and poeciliid fishes used in this study, after Ghedotti (2000); outgroup relationships as summarized from Costa (1997) and Parenti (2005)

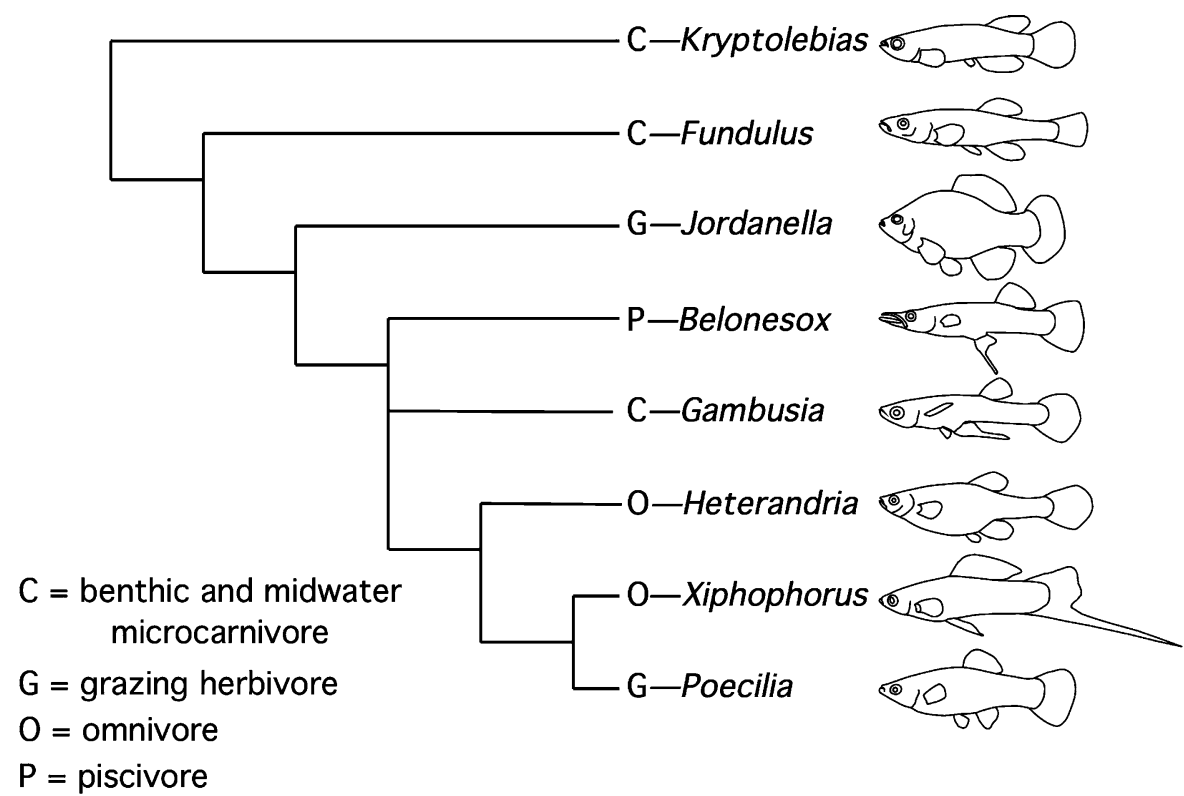


Kryptolebias marmoratus, Rivulidae) were acquired from commercial vendors. Fish were maintained in the lab in 38-1 glass aquaria at ambient lab temperature $\left(22 \pm 1^{\circ} \mathrm{C}\right)$ on a $12: 12$ light/dark cycle. Fish were provided with a variety of food items during acclimation, including flake and pellet foods consisting primarily of a mixture of fish and algal meals, larval chironomids, brine shrimp, and live guppies. All animal care and experimentation for this study were conducted according to a Northern Arizona University Institutional Animal Care and Use Committee approved protocol (NAU IACUC \#04-007).

Feeding trials and digital imaging

For feeding trials, fish of a given species were placed into a 7.5-1 glass or transparent-acrylic imaging chamber that was subdivided into three sections by glass or acrylic partitions. In most instances, a single individual was placed in each subsection of the tank. However, some species (e.g. Heterandria) preferred to feed in small schools; for these species, two or three individuals that could be distinguished from one another based on size, sex, or coloration or some combination of these characteristics were placed in each subsection of the tank. Individuals of each species were acclimated to the imaging chamber for two to $24 \mathrm{~h}$ before the feeding trials began.

During the feeding trials, the imaging chambers were illuminated using $600-\mathrm{W}$ tungsten lights and individual feeding events were recorded using a Redlake Motionscope PCI1000s capturing digital images at 250 frames per second. To stimulate feeding from the substrate, fish were presented with solid food items located on the bottom of the imaging chamber (Fig. 3). The food item presented to the fish was either physically attached to the bottom with a small drop of silicone, or so large as to be impossible for the fish to dislodge during feeding. Fish were presented with either commercial sinking pellet food or custommade brine-shrimp gelatin cubes consisting of frozen brine shrimp and gelatin powder. To eliminate potential effects of prey type on cranial movements, the target species for which kinematic data were measured were fed brine-shrimp gelatin cubes. For all target species, at least four individuals were recorded feeding, and at least four events were captured for each individual. After the feeding experiments, individuals were anesthetized, weighed, measured, euthanized, and preserved for ongoing morphological studies.

Kinematic analysis

Based on preliminary observations of behavior of feeding events, male and female individuals of each of the following four target species were selected for kinematic analysis: Gambusia affinis $(n=4$; standard length $=19.3-22.2 \mathrm{~mm})$, Heterandria formosa $(n=4$; standard length $=16.0-22.7 \mathrm{~mm}$ ), Xiphophorous helleri ( $n=5$; standard length=40.4 $44.4 \mathrm{~mm})$, and Poecilia sphenops $(n=6$; standard length $=36.9-47.8 \mathrm{~mm})$. Three of these species demonstrated intramandibular bending and the fourth (Gambusia) is a close relative. Another close relative, Belonesox belizanus, displayed no intramandibular bending and would only feed on live prey presented in the water column; therefore, this species was not included in the kinematic analysis. Outgroup taxa Jordanella floridae, Fundulus rubrifrons and Kryptolebias marmoratus all displayed no intramandibular bending when feeding from the bottom or in the water column - thus, these fish were also not included in kinematic analyses. For the target species selected for kinematic analysis (Gambusia, Heterandria, Xiphophorus, Poecilia), movie files (AVI) recorded by the Redlake Motionscope system were exported as a series of sequential TIFF files. TIFF files were then imported into NIH Image-J (ver. 1.62, Macintosh OS X), where four kinematic variables were measured from the frames immediately before and during contact with the food item (approximately 20 sequential frames in total). Kinematic variables measured from anatomical landmarks (Fig. 4) were as follows: neurocranial rotation (an angle defined by a vertical line posterior to the eye, a second line along the top of the skull directly above the eye, and a vertex at the point where these two lines intersect); lower jaw depression (an angle defined by a line following the ventral margin of the angular-articular bone complex that forms the posterior lower jaw, a line from the anterior margin of the dorsal fin to the base of the lower jaw, and a vertex where these two lines intersect at the joint between the quadrate and the posterior lower jaw); gape angle (an angle defined by a line along the anteriorventral margin of the upper jaw, a second line along the anterior-dorsal margin of the lower jaw, and a vertex at the juncture between the upper and lower jaws - as the upper and lower jaws move farther apart, the gape angle 

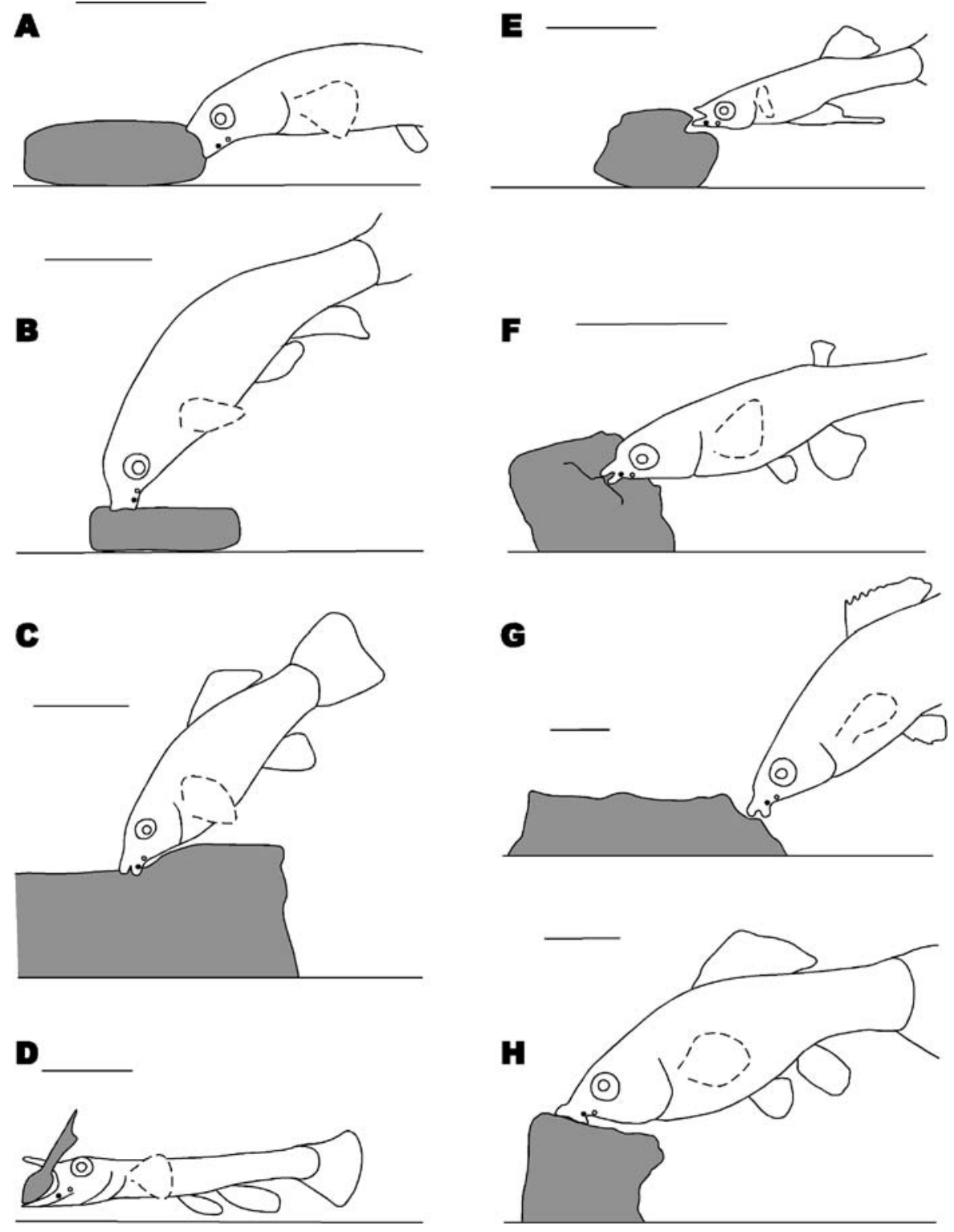

Fig. 3 Line drawings constructed using high-speed video recordings of feeding behavior in eight cyprinodontiform species. To prepare the figure, individual images were selected, cropped, flipped horizontally as necessary (to place all fish in the same relative orientation) and the brightness and contrast were manipulated to enhance the image; images were selected to represent the maximum amount of lower jaw depression or intramandibular bending produced during the feeding event for each species. Images were individually imported into an illustration program (Canvas ver.X for Mac OS X) and the outlines of the fish and food item were traced manually; the outline of the pectoral fin is shown in a dashed line as it represents the approximate location of this structure in the frame. Each panel represents a different species, with the four target Poeciliid species comprising the four panels on the right; species are as follows: a Kypotolebias marmoratus, b Fundulus

rubrifrons, c Jordanella floridae, d Belonesox belizanus, e Gambusia affinis, f Heterandria formosa, g Xiphophorus helleri, h Poecilia sphenops. Two circles on each image represent the approximate location of the two jaw joints (as determined from morphological analysis of specimens in combination with video-image analysis): The white circle indicates the articulation between the suspensorium and the posterior mandible, the black circle indicates the articulation between the anterior mandible (dentary) and the posterior mandible (angular-articular). Species shown in $\mathbf{a}$ and $\mathbf{b}$ are feeding on a pellet of commercial food, species in $\mathbf{c}$ and $\mathbf{e}-\mathbf{h}$ are feeding on a block of gelatin containing brine shrimp (see text) and the species in $\mathbf{d}$ is consuming a small fish; scale bar in each panel represents $1 \mathrm{~cm}$. The digital movies from which these still images were constructed can be found online: http://jan.ucc. nau.edu/acg/ebfmovies/ 

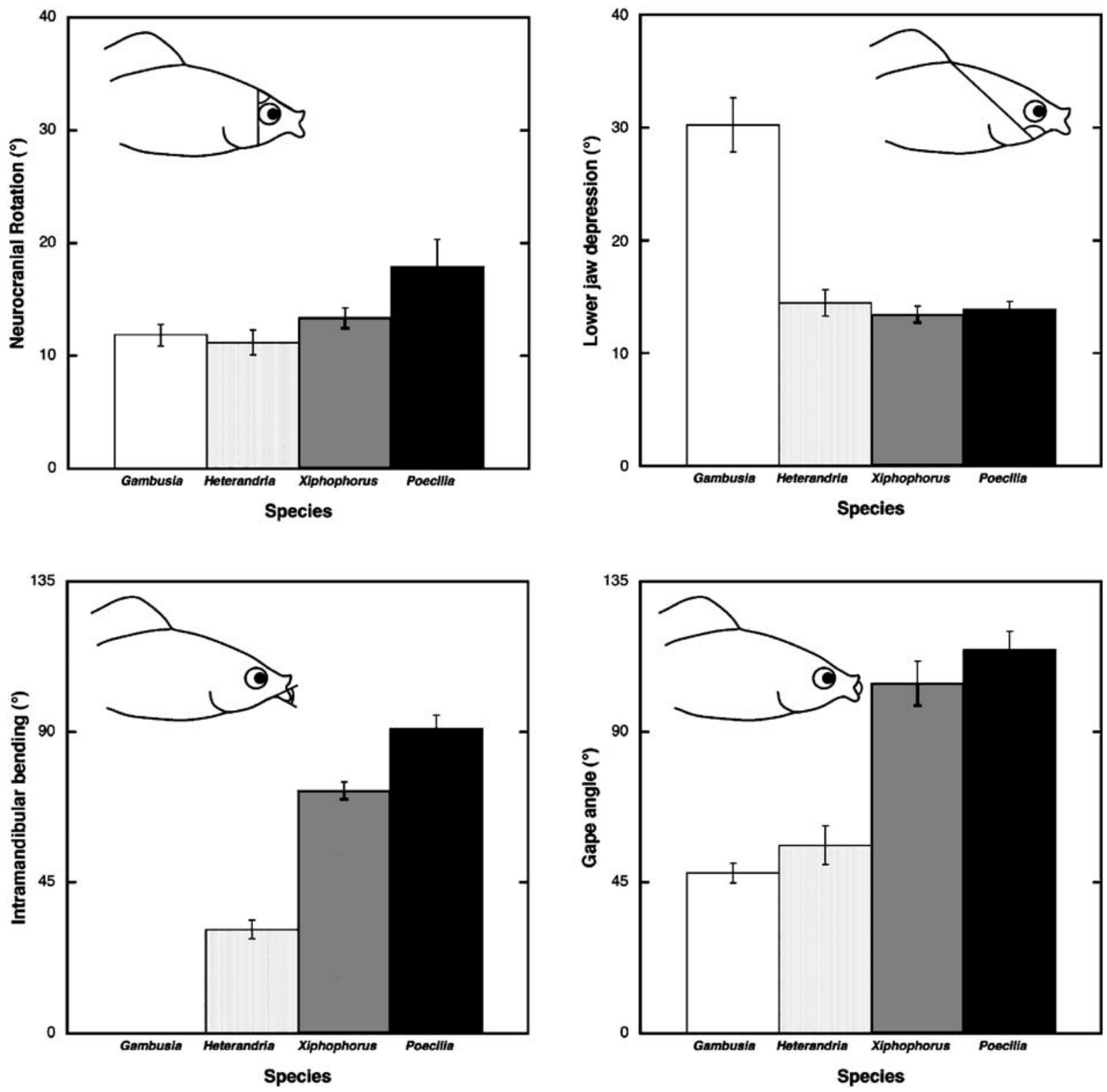

Fig. 4 Graphs of four kinematic variables measured in this study. Each panel represents a different angular variable: Variable names are given beside each graph, species names are given below each graph. A cartoon representing an

approaches $180^{\circ}$ ); intramandibular bending (an angle defined by a line along the ventral margin of the dentary bone that forms the anterior lower jaw, a second line along the ventral margin of the angular-articular bone complex that forms the posterior lower jaw, and the vertex at the juncture of these two lines). For intramandibular bending, the angle measured was subtracted from $180^{\circ}$ to determine the deviation from an a priori

individual Poecilia sphenops is given within each graph to demonstrate how that variable was defined; see text for additional details

expectation of no intramandibular bending (see illustration of calculated angle in Fig. 4). Maximal values for each of these four angles (maximum neurocranial rotation, maximum lower jaw depression, maximum gape angle, and maximum intramandibular bending) were recorded for every feeding event $(n=3-5)$ for each individual in all four species (total number of feeding events $=111$ ). 
Statistical comparisons

Kinematic values for each feeding sequence were used to determine variable means for each individual. Individual means were then input into Statview (v. 5.0.1, Macintosh OS 9) and used to generate a one-factor MANOVA with species considered as the main effect to test the hypothesis that the four target species differed from one another in quantitative aspects of feeding behavior. Given a significant MANOVA result, sequential one-factor ANOVAs were performed for each of the kinematic variables to determine which varied among the target species.

\section{Results}

Of the eight species initially examined in this study, one species, Belonesox belizanus, was consistently unwilling to feed on inanimate prey positioned on the floor of the tank. This species is highly modified for piscivory (Gregory 1933) and will only feed on live prey items moving in the water column or just above the substrate (Fig. 3). Morphological modifications and feeding behavior of this species are considered in detail elsewhere (Pace and Gibb 2005); however, we note that Belonesox demonstrates no intramandibular bending when feeding on live prey.

The other cyprinodontiform species were all willing to consume inanimate food located on the bottom of the tank; all seven of these species would readily approach the food item and attempt to pick or scrape pieces of the item off the substrate. Kryptolebias and Fundulus produced very similar behaviors to one another when feeding on food attached to the substrate: individuals of both species would approach the food item (from either the upper surface or the side), rotate the mandible ventrally (via lower jaw depression), and project the upper jaw (via upper jaw protrusion) toward the item (Fig. 3). Because a lip ligament connects the upper and lower jaws (Ferry-Graham et al. in press) these movements created a broad, tube-shaped mouth, with the anterior tips of the upper and lower jaws placed in direct contact with the food item (Fig. 3a,b). During mouth closing, the tips of the jaws were brought together rapidly; in this manner, it appeared that fish scraped material from the surface of the food item.

The initial stage of the substrate-feeding behavior of Jordanella appeared similar to that of Kryptolebias and Fundulus: individuals of this species would approach the food item from either the upper surface or the side and depress the lower jaw while projecting the upper jaw toward the food item. However, during substrate-feeding in Jordanella, the jaws formed a more delicate, beak-like structure rather than a tubelike structure. Using the oral jaws as pinchers, Jordanella appeared to "pluck" or "nip" small pieces of food from the edges of the food item (Fig. 3c). This behavior is similar to a behavior previously described for Jordanella feeding on periphyton (Foster 1967).

The four target poeciliid species all produced notably different behaviors during the feeding trials. Gambusia tended to approach the prey from the side and would often attempt to procure food from the block using suction feeding: as the lower jaw was depressed and the upper jaw protruded, the hyoid region (i.e. the "throat" or gular region, ventral to the eye) was depressed, and small pieces of brine shrimp moved toward the mouth of the fish. However, because the brine shrimp were imbedded in the gelatin cube, they could not be dislodged by suction. Instead, the upper and lower jaws clamped down, and Gambusia would tear a piece of food from the cube (Fig. 3e).

Heterandria would approach the food from the side or the surface like Fundulus and Kryptolebias and extend the jaws toward the food. However, in Heterandria, the upper and lower jaws formed a small, beak-shaped structure during mouth opening that protruded ventrally (toward the food). During feeding, there was a slight, but obvious bend in the lower jaw, where the dentary rotated ventrally, relative to the angular-articular. This movement appeared to facilitate contact between the tip of the dentary and the food (Fig. 3f), and the upper jaw appeared to follow the movements of the lower jaw (i.e. it also moved ventrally during mouth opening). The tips of the upper and lower jaws were brought together rapidly during mouth closing, and, as with Jordanella, Heterandria appeared to pluck a small piece of food from the surface of the food item.

Xiphophorus and Poecilia were generally similar to one another in their substrate-feeding behaviors, although all aspects of this behavior were more extreme in Poecilia. In both species, fish would typically approach the food item from above. During lower jaw depression, the anterior region of the mandible would bend ventrally, toward the food item. 
In both species, but particularly in Poecilia, the jaws "flared" during feeding - that is, the upper jaw appeared to move dorsally or anteriorly while the lower jaw moved ventrally, creating a very wide gape. This wide gape allowed the tips of the upper and lower jaws to be placed on the surface of the food item during mouth opening and enabled a large region of the food to be scraped by the tips of the jaws during mouth closing (Fig. 3g,h).

Comparisons of the kinematic variables among the four target species (Gambusia, Heterandria, Xiphophorus and Poecilia) also indicated that the species differed from one another in the overall movements used to procure encrusting food (MANOVA WilksLambda $F=4.7, p<0.001$ ). These taxa demonstrated differences in three of the four kinematic variables (all $F>10.5, p<0.001$ ); only neurocranial rotation did not differ among the target species $(F=1.4, p>0.05$; Fig. 4).

The four target species varied in the degree of lower jaw depression produced (Fig. 4), such that Gambusia produced the greatest amount of rotation (approximately $30^{\circ}$ ) at the joint between the posterior region of the lower jaw and the quadrate. Interestingly, Gambusia displayed no intramandibular bending, while the other three species all produced some bending. However, these species varied in the degree of bending produced, with Heterandria producing the least (approximately $30^{\circ}$ ) and Poecilia the most $\left(>90^{\circ}\right.$, Fig. 4). Gape angle also varied among taxa, with Poecilia also showing the largest gape angle (>120 $0^{\circ}$ Fig. 4).

\section{Discussion}

Depression of the lower jaw at the quadratomandibular joint by suction-feeding teleosts typically involves relatively little $\left(\sim 30^{\circ}\right)$ lower jaw rotation (Gibb and Ferry-Graham 2005). This limited rotation likely enables the formation of a small, round mouth-aperture during suction feeding, which should enhance the efficacy of this feeding mode (Wainwright and Day 2007). However, this relatively small degree of rotation may also reduce the ability of the fish to effectively apply its teeth to a food item attached to the substrate, generating a potential functional trade-off between these two feeding modes.
Many teleost species that have undergone a trophic shift to encrusting or epiphytic food materials have concomitantly acquired an intramandibular joint (Konow et al. 2008). However, other teleost speciesfor example, certain species in the Blenniidae and Cichlidae - also rely on attached algae as their primary food source, but do not appear to possess an intramandibular joint (Lindquist and Dillaman 1986; Bouton 1998). Perhaps most impressively, the large and successful loricariid catfishes feed predominantly on algae and detritus, but do not appear to demonstrate any intramandibular bending (Schaefer and Lauder 1986). The success of these groups suggests either that the rotation of the lower jaw about the quadratomandibular joint does not intrinsically limit scraping performance, or that alternate biomechanical changes to the feeding apparatus have enabled these fish to "escape" this potential constraint (Schaefer and Lauder 1986). Thus, intramandibular bending is not required to "solve" the "problem" of feeding on encrusting materials. Yet, many species have independently evolved a second lower jaw joint, which raises the question: what is the advantage of a second jaw joint?

In fish with intramandibular bending, it is possible that retention of the "typical" jaw rotation at the quadrato-mandibular joint preserves suction-feeding ability while simultaneously enhancing substratefeeding ability. For example, in the surgeonfish (Acanthuridae), rotation occurs concomitantly at the quadrato-mandibular joint and at the intramandibular joint (Purcell and Bellwood 1993); these two rotations combine to produce a large gape angle. Thus, it is possible that species with intramandibular bending could produce a functionally smaller gape if only quadrato-mandibular rotation is employed when feeding in the water column. Thus, "double-jointed" fish could retain suction-feeding performance while simultaneously improving feeding performance on encrusting food items - thereby avoid a functional trade-off. Some poeciliids still produce intramandibular bending while feeding on small prey-items floating in the water column (Gibb and Blanton 2004), which does not support this hypothesis. However, it is possible that the inanimate food presented (dead chironomid larvae) does not represent a sufficient stimulus to trigger a maximal feeding effort.

Another possible benefit of intramandibular bending is that it may allow a change of the position of the 
body in the water column during substrate feeding. Fish that feed on the benthos face a potential problem not encountered by fish that feed in the water column: procuring prey from the bottom may necessitate reorienting the entire body toward the bottom to allow the jaws to make contact with the substrate. In this position, the fish is no longer in the appropriate posture to either detect predators visually, or to produce an effective escape behavior-the latter because the fish will have difficulty reorienting to avoid the substrate when attempting to escape. Intramandibular bending, however, may allow a fish to keep its body more parallel to the substrate while feeding, which should facilitate the visual detection of potential predators and the production of effective escape responses, thereby increasing the probability of avoiding capture (Bellwood 1994). This potential advantage may also explain the ventrally-directed jaw protrusion seen in omnivores that employ suction feeding to feed on the benthos (Motta 1984). The ability to maintain vigilance while feeding may be even more important for benthic herbivores, which spend a large proportion of their time grazing (Dussault and Kramer 1981; Bellwood 1994).

In an a posteriori test of this hypothesis, we examined the angle of the body relative to the substrate at the moment of maximal jaw depression or intramandibular bending in all feeding events for all individuals of the four target species examined in this study $(n=111)$. Surprisingly, species examined here did not differ significantly in their body angle relative to the substrate (ANOVA $F=1.0, p>0.40$; mean for all species $\sim 25^{\circ}$ ). However, species without intramandibular bending would often attack the food item from the side, thus allowing these fish to adopt a much shallower angle during feeding that would be possible with a truly encrusting material (e.g. Gambusia, Fig. 3e). In addition, it is likely that fish with intramandibular bending chose not to adopt a shallow posture when feeding in the laboratory in the absence of potential predators, as there is no perceived threat under these artificial conditions. However, our observations suggest that species with large degrees of intramandibular bending can scrape material from the upper surface of the food using very shallow attack angles, relative to non-bending species (e.g. Poecilia sphenops vs. Fundulus rubrifrons, Fig. 3b,h).

Intramandibular bending also allows a large gape angle (approaching $180^{\circ}$ ) to be formed by the mouth during feeding. This large angle likely allows the anterior tips of the upper and lower jaws to be placed in direct contact with a flat surface, although it is important to note that movements of the ventral arm of the maxilla and/or the membrane associated with the lips and anterior jaws may confound the measurement of gape angle (Gibb 1996; Horn and FerryGraham 2006). During substrate feeding, the jaws of Poecilia sphenops are spread wide to enable a very large bite to be taken from a flat substrate (Fig. 3h), and the toothed surfaces of the upper and lower jaws are placed in direct contact with the food item; as the jaws close, encrusting material encompassed by the tips of the jaws is scraped into the mouth. Smaller gape angles in Gambusia affinis and outgroup species generate smaller gapes (Fig. 3) that likely result in less material being captured during a single bite (Bouton 1998).

Several species of poeciliid rely heavily or entirely on attached algae (periphyton) in their diet (Hunt 1953; Zaret and Rand 1971; Arthington 1989; Alkahem et al. 2007). Interestingly, the four target species of poeciliid we examined here demonstrate different degrees of intramandibular bending, and this variation in bending appears to be associated with different levels of reliance on periphyton as a food source (Table 1). Herbivorous species, such as Poecilia sphenops, generate a large degree of intramandibular bending, whereas species that consume primarily zooplankton (Gambusia affinis) produce none, and species with mixed diets (Heterandria formosa and Xiphophorus helleri) have intermediate bending (Hunt 1953; Zaret and Rand 1971; Hurlbert and Mulla 1981; Arthington 1989; Belk and Lydeard 1994; Schaefer et al. 1994). This apparent correlation between diet and intramandibular bending within the Poeciliidae provides support for the evolutionary hypothesis that intramandibular bending provides a functional advantage when feeding on encrusting or attached food items. Tooth morphology (Hernandez et al. in press) also supports this association: poeciliid species that produce intramandibular bending have spatulate teeth (Table 1), a trait associated with herbivory (Delariva and Agostinho 2001). Gambusia, Belonesox and two outgroup species have conical teeth and omnivorous or carnivorous diets (Table 1).

However, we note that one outgroup species, the flagfish Jordanella floridae, also relies heavily on attached algae in the diet (Hunt 1953; Loftus 2000), 
Table 1 Intramandibular bending, tooth morphology, trophic guild and diet composition in selected cyprinodontiform taxa as summarized from this study and available literature

\begin{tabular}{|c|c|c|c|}
\hline Species & $\begin{array}{l}\text { Intramandibular } \\
\text { bending? }\end{array}$ & Tooth morphology & Trophic guild: primary diet \\
\hline Kryptolebias marmoratus & No & Conical $^{\mathrm{a}}$ & Carnivore: aquatic and terrestrial invertebrates ${ }^{\mathrm{b}, \mathrm{c}}$ \\
\hline Fundulus rubrifrons & No & Conical $^{\mathrm{a}}$ & Carnivore? ${ }^{\mathrm{d}}$ \\
\hline Jordanella floridae & No & Tricuspid; iron-tipped ${ }^{\mathrm{a}}$ & Grazing herbivore: periphyton ${ }^{\mathrm{e}-\mathrm{g}}$ \\
\hline Belonesox belizanus & No & Conical $^{\mathrm{a}}$ & Piscivore: fish ${ }^{\mathrm{g}, \mathrm{h}, \mathrm{i}}$ \\
\hline Gambusia affinis & No & Conical $^{\mathrm{a}}$ & Carnivore: aquatic invertebrates and fish ${ }^{\mathrm{g}-1}$ \\
\hline Heterandria formosa & Yes: $\sim 30^{\circ}$ & Spatulate; iron-tipped ${ }^{\mathrm{a}}$ & Omnivore: aquatic invertebrates and some periphyton ${ }^{\mathrm{e}, \mathrm{g}, 1}$ \\
\hline Xiphophorus helleri & Yes: $\sim 70^{\circ}$ & Spatulate; iron-tipped ${ }^{\mathrm{a}}$ & Omnivore: aquatic invertebrates and periphyton ${ }^{\mathrm{m}}$ \\
\hline Poecilia sphenops & Yes: $\sim 90^{\circ}$ & Spatulate; iron-tipped ${ }^{\mathrm{a}}$ & Grazing herbivore: periphyton ${ }^{\mathrm{n}}$ \\
\hline
\end{tabular}

${ }^{\mathrm{a}}$ Hernandez et al. in press

${ }^{\mathrm{b}}$ Huehner et al. 1985

${ }^{\mathrm{c}}$ Taylor 1992

${ }^{\mathrm{d}}$ No diet data for this species were found in the literature. Trophic guild given here is based on that reported for other Fundulus species that occupy similar habitats (Hunt 1953; Rozas and LaSalle 1990).

${ }^{\mathrm{e}}$ Hunt 1953

${ }^{\mathrm{f}}$ Foster 1967

${ }^{g}$ Loftus 2000

${ }^{\mathrm{h}}$ Belshe 1961

${ }^{\mathrm{i}}$ Andersson 1986

${ }^{\mathrm{j}}$ Hurlbert and Mulla 1981

${ }^{\mathrm{k}}$ Belk and Lydeard 1994

${ }^{1}$ Schaefer et al. 1994

${ }^{\mathrm{m}}$ Arthington 1989

${ }^{\mathrm{n}}$ Zaret and Rand 1971

as do other species in the large and successful family Cyprinodontidae (Foster 1967; Davis 1981). Thus, it is surprising that intramandibular bending is not present in the species we selected to represent this group. In addition, Jordanella have tricuspid teeth (Hernandez et al. in press), a tooth morphology also associated with herbivory (Albertson et al. 2003). Thus, trophic habit and tooth morphology of Jordanella suggest that intramandibular bending should enhance feeding performance in this group, yet this mechanism is not present.

One possible explanation for this counter-intuitive result is that diversity in the morphology of periphyton allows several effective foraging strategies. In freshwater systems, the components of periphyton can be placed in two general structural classes: filamentous algae or diatoms, which tend to grow upward (toward the light), and non-filamentous algae or diatoms, which encrust the substrate (Zedler 1980; Feminella and Resh 1991; Biggs and Thomsen 1995;
Steinman 1996; Geddes and Trexler 2003). Benthic invertebrates are often found at high densities within the microhabitat created by these periphyton assemblages (Towns 1981; Power 1990). We suggest that intramandibular bending facilitates a particular mode of feeding on periphyton: scraping the teeth of the upper and lower jaws though the encrusting periphyton to remove either the encrusting material itself (as in Poecilia) or the resident microinvertebrates (as in Xiphophorus). Jordanella, in contrast, appear to use a different tactic when feeding in the periphyton: They grab filaments of attached algae/diatoms with the tips of the anterior jaws and rip them from the substrate (Foster 1967); Jordanella removed pieces from the attached food items used in this study with a similar "nipping" behavior. It is not immediately clear how intramandibular bending could enhance the effectiveness of this feeding method, which may explain why it has not evolved in Jordanella. However, recent work on angelfishes (Pomacanthidae) suggests that 
anglefish do produce intramandibular bending while employing a "grab-and-tearing" feeding behavior (Konow et al. 2008).

All too often when an advantageous novel structure or behavior evolves in a group, intermediate forms vanish; this problem has vexed biologists ever since Darwin (1859). Interestingly, under certain phylogenetic hypotheses (Ghedotti 2000), intramandibular bending appears to represent a transformational series found in derived members of this family (Fig. 5). However, an alternate and potentially controversial phylogeny for this group has recently been proposed (Hrbek et al. 2007). This alternate phylogeny suggests that intramandibular bending may have evolved within this family more than once, or, more parsimoniously, that it evolved once in ancestral poeciliids and has been secondarily lost in a single carnivore lineage (Fig. 5). Under either phylogenetic scenario, the close association of intramandibular bending with trophic niche warrants further investigation.

As previously noted, many marine species that feed on algae or other encrusting food items demonstrate intramandibular bending, as do kissing gourami Helostoma temminckii; we have now documented intramandibular bending in several species of substrate-feeding poeciliid. A morphologically distinct, but functionally similar, second jaw joint has arisen in all species that possesses this mechanism (Liem 1967; Konow et al. 2008). Indeed, our preliminary morphological analyses suggest that this movement occurs via a previously unrecognized mechanism in the

Fig. 5 Simplified cladograms illustrating two possible evolutionary hypotheses of the relationships among poeciliids examined in this study; in both panels, the three species that demonstrate intramandibular bending are shown in boxes. a Relationships of selected poeciliid taxa based on morphological characters following Ghedotti (2000), as in Fig. 2. b Relationships of selected poeciliid taxa based on molecular characters, following Hrbek et al. (2007). For both cladograms, outgroup relationships as summarized from Costa (1997) and Parenti (2005). Under phylogenetic hypothesis A, the various states of intramandibular bending may represent a transformation series within derived poeciliids, with Heterandria demonstrating the least intramandibular bending and Poecilia the most. Under hypothesis B, intramandibular bending has either evolved multiple times within the Poeciliidae, or, more parsimoniously, evolved once in ancestral poeciliids and has been secondarily lost in a carnivore lineage. Additional phylogenetic and behavioral studies are necessary to distinguish between these various possibilities
Poeciliidae (Gibb and Blanton 2004). Thus, studies are in progress to describe the morphology and material properties of the intramandibular joint in this group. However, we note that most taxa with intramandibular bending described to date (including poeciliids) demonstrate an apparent dissociation of the dentary (the anterior element) from the angulararticular (the posterior element), with kissing gourami being the only potential exception (Liem 1967). Future developmental studies may elucidate the processes that allow this apparent evolutionary plasticity in lower jaw morphology.

A

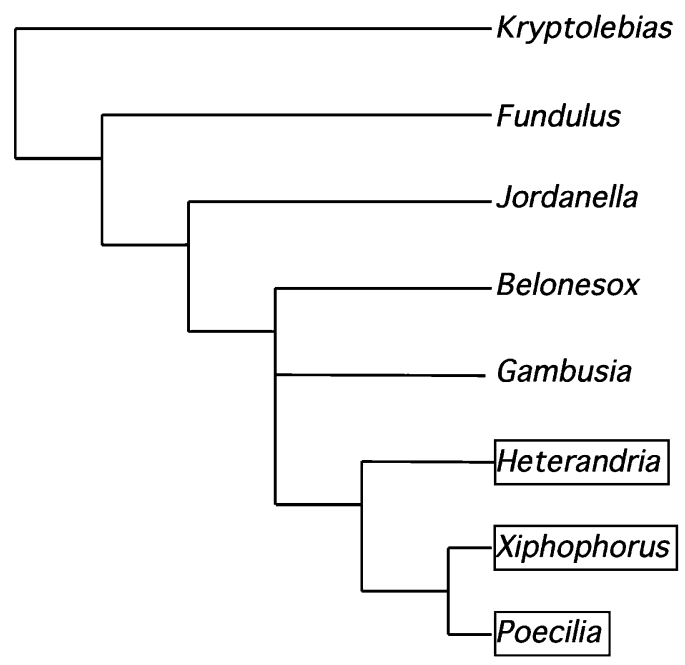

B

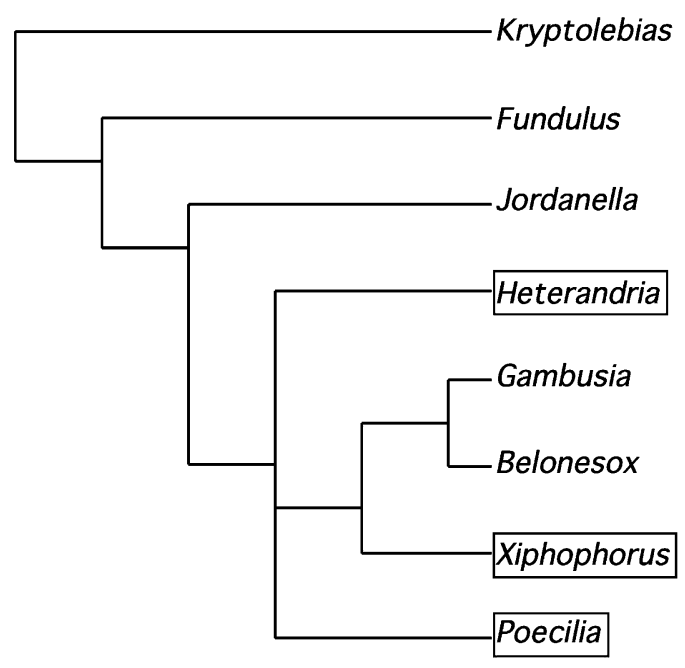


We conclude by noting that intramandibular bending cannot be predicted from morphological analysis alone. Detailed morphological studies of taxa eventually shown to have intramandibular bending have been conducted without the researcher detecting the potential for intra-jaw bending (Gregory 1933). Thus, additional functional studies conducted in the laboratory using known benthic feeders consuming food items attached to the substrate are necessary to determine how widespread this behavior is among teleosts. We predict that future experiments using representatives of herbivorous, freshwater teleost lineages will yield additional examples of convergent evolution of this under-appreciated feeding mechanism.

Acknowledgement Support for this research was provided by a Northern Arizona University (NAU) Intramural Grant and a Science Foundational Arizona Competitive Advantage Award (CAA 0057-07) to ACG. Additional funding was provided through NSF DBI-0243914, "Research internships in neural and behavioral sciences," to S. Shuster and V. Blankenship of NAU; this NSF grant supplied summer stipends and funds for laboratory supplies for JB and RR, who conducted the majority of the feeding behavior trials reported in this study. Jenny Eckels collected additional behavioral data for the outgroup species included here. Matt O’Neill, Cinnamon Pace, Teresa Hunt, Anthony Arena and Brandon Melville provided technical support and helpful comments on early versions of the manuscript. We also thank Peter Wainwright, an anonymous reviewer, and the editors at Environmental Biology of Fishes for their thoughtful comments.

\section{References}

Albertson RC, Streelman JT, Kocher TD (2003) Directional selection has shaped the oral jaws of Lake Malawi cichlid fishes. Proc Natl Acad Sci USA 100:5252-5257

Alkahem HF, Al-Ghanim AA, Ahmad Z (2007) Studies on feeding ecology of sailfin molly (Poecilia latipinna) dwelling in Wadi Haneefah stream, Riyadh. Pak J Biol Sci 10:335-341

Andersson M (1986) Geographic variation and aspects of the life history of Belonesox belizanus Kner (Pisces: Poeciliidae) from Central America. Northern Illinois University, DeKalb, IL, USA

Arthington AH (1989) Diet of Gambusia affinis holbrooki, Xiphophorus helleri, X. maculatus and Poecilia reticulata (Pisces: Poeciliidae) in streams of southeastern Queensland, Australia. Asian Fish Sci 2:193-212

Belk MC, Lydeard C (1994) Effect of Gambusia holbrooki on a similar-sized, syntopic poeciliid, Heterandria formosa: competitor or predator? Copeia 1994:296-302

Bellwood DR (1994) A phylogenetic study of the parrotfishes family Scaridae (Pisces: Labroidei), with a revision of genera. Rec Aust Mus Suppl 20:1-86
Belshe JF (1961) Observations on an introduced tropical fish, Belonesox belizanus, in southern Florida. MS, Department of Biology, University of Miami, Coral Gables, Florida, p 73

Biggs BJF, Thomsen HA (1995) Disturbance of stream periphyton by perturbations in shear stress: time to structural failure and differences in community resistance. J Phycol 31:233-241

Bouton N (1998) Feeding performance of Lake Victoria rock cichlids: testing predictions from morphology. J Fish Biol 53:118-127

Costa W (1997) Phylogeny and classification of the Cyprinodontidae revisited (Teleostei: Cyprinodontiformes): are Andean and Anatolian killifishes sister taxa? J Comput Biol 2:1-17

Darwin C (1859) On the origin of species by natural selection. Murray, London, p 458

Davis JR (1981) Diet of the Pecos River pupfish, Cyprinodon pecosensis (Cyprinodontidae). Southwest Nat 25:535-540

Delariva R, Agostinho A (2001) Relationship between morphology and diets of six neotropical loricariids. J Fish Biol 58:832-847

Dussault GV, Kramer DL (1981) Food and feeding behavior of the guppy, Poecilia reticulata (Pisces: Poeciliidae). Can J Zool 59:684-701

Feminella JW, Resh VH (1991) Herbivorous caddisflies, macroalgae, and epilithic microalgae: dynamic interactions in a stream grazing system. Oecologia 87:247-256

Ferry-Graham LA, Gibb AC, Hernandez LP (in press) Premaxillary movements in cyprinodontiform fishes: an unusual protrusion mechanism facilitates "picking" prey capture. Zoology

Foster NR (1967) Comparative studies on the biology of killifishes (Pisces, Cyprinodontidae), Cornell University, 369 pp

Geddes P, Trexler JC (2003) Uncoupling of omnivore-mediated positive and negative effects on periphyton mats. Oecologia 136:585-595

Ghedotti MJ (2000) Phylogenetic analysis and taxonomy of the poecilioid fishes (Teleostei: Cyprinodontiformes). Zool J Linn Soc 130:1-53

Gibb A (1996) The kinematics of prey capture in Xystreurys liolepis: do all flatfish feed asymmetrically? J Exp Biol 199:2269-2283

Gibb A, Blanton J (2004) Is there a free lunch? Elastic recoil and herbivory in Poecilia sphenops. Integ Comp Biol 44:42.3

Gibb AC, Ferry-Graham L (2005) Cranial movements during suction feeding in teleost fishes: are they modified to enhance suction production? Zoology 108:141-153

Gregory WK (1933) Fish skulls: A study of the evolution of natural mechanisms. Trans Am Philos Soc 23:416

Hernandez LP, Gibb AC, Ferry-Graham LA (in press) Transformation of the trophic apparatus in cyprinodontiform fishes: functional specializations for picking and scraping behaviors. Journal of Morphology

Horn MH, Ferry-Graham LA (2006) Feeding mechanisms and trophic interaction. The ecology of marine fishes: California and adjacent waters. University of California Press, Berkeley, CA, pp 387-410

Hrbek T, Seckinger J, Meyer A (2007) A phylogenetic and biogeographic perspective on the evolution of poeciliid fishes. Mol Phylogenet Evol 43:986-998 
Huehner MK, Schramm ME, Hens MD (1985) Notes on the behavior and ecology of the killifish Rivulus marmoratus Poey 1880 (Cyprinodontidae). Fla Sci 48:1-6

Hunt BP (1953) Food relationships between Florida spotted gar and other organisms in the Tamiami Canal, Dade County, Florida. Trans Am Fish Soc 82:13-33

Hurlbert SH, Mulla MS (1981) Impacts of mosquitofish (Gambusia affinis) predation on plankton communities. Hydrobiologia 83:125-151

Konow N, Bellwood DR (2005) Prey-capture in Pomacanthus semicirculatus (Teleostei, Pomacanthidae): functional implications of intramandibular joints in marine angelfishes. J Exp Biol 208:1421-1433

Konow N, Bellwood DR, Wainwright PC, Kerr AM (2008) Evolution of novel joints promote trophic diversity in colar reef fishes. Biol J Linn Soc 93:545-555

Lauder GV (1985) Aquatic feeding in lower vertebrates. In: Hildebrand $M$ (ed) Functional vertebrate morphology. Belknap Press of Harvard University Press, Cambridge, MA, pp 210-229

Liem KF (1967) Functional morphology of the head of the anabantoid teleost fish Helostoma temmincki. J Morphol 121:135-157

Lindquist DG, Dillaman RM (1986) Trophic morphology of four western Atlantic blennies (Pisces: Blenniidae). Copeia 1986:207-213

Loftus WF (2000) Accumulation and fate of mercury in an everglades aquatic food web. Ph.D. dissertation, Florida International University, $295 \mathrm{pp}$

Matthews WJ (1998) Patterns in freshwater fish ecology. Chapman and Hall, New York, NY, p 756

Meffe GK, Snelson FF (1989) An ecological overview of poeciliid fishes. Ecology and evolution of livebearing fishes (Poeciliidae). Prentice Hall, Englewood Cliffs, NJ, pp 13-31

Motta PJ (1984) Mechanics and functions of jaw protrusion in teleost fishes: A review. Copeia 1984:1-18

Pace C, Gibb AC (2005) Feeding kinematics of the pike killifish, Belonesox belizanus, a predominantly piscivorous poeciliid. Integ Comp Biol 45:73.3

Parenti LR (2005) The phylogeny of atherinomorphs: evolution of a novel fish reproductive system. In: Grier HJ, Uribe MDC (eds) Viviparous fishes. Proceedings of the I and II International Symposia. New Life Publications, Homestead, FL, pp 13-30

Power ME (1990) Benthic turfs vs floating mats of algae in river food webs. Oikos 58:67-79

Purcell SW, Bellwood DR (1993) A functional analysis of food procurement in two surgeonfish species, Acanthurus nigrofuscus and Ctenochaetus striatus (Acanthuridae). Environ Biol Fishes 37:139-159

Rozas LP, LaSalle MW (1990) A Comparison of the diets of Gulf killifish, Fundulus grandis Baird and Girard, entering and leaving a Mississippi brackish marsh. Estuaries 13:332-336

Schaefer SA, Lauder GV (1986) Historical transformation of functional design: evolutionary morphology of feeding mechanisms in loricarioid catfishes. Syst Zool 35:489508

Schaefer JF, Heulett ST, Farrell TM (1994) Interactions between two poeciliid fishes (Gambusia holbrooki and Heterandria formosa) and their prey in a Florida marsh. Copeia 1994:516-520

Springer VG (1988) The Indo-Pacific bleniid fish genus Escenius. Smithson Contrib Zool 465:1-134

Steinman AD (1996) Effects of grazers on freshwater benthic algae. In: Stevenson R, Bothwell M, Lowe R, Thorpe J (eds) Algal ecology: freshwater benthic ecosystems. Academic, New York, pp 341-373

Streelman JT, Alfaro M, Westneat MW, Bellwood DR, Karl SA (2002) Evolutionary history of the parrotfishes: biogeography, ecomorphology, and comparative diversity. Evolution 56:961-971

Taylor DS (1992) Diet of the killifish Rivulus marmoratus collected from land crab burrows, with further ecological notes. Environ Biol Fishes 33:389-393

Towns DR (1981) Effects of artificial shading on periphyton and invertebrates in a New Zealand Stream. N Z J Mar Freshw Res 15:185-192

Vial CI, Ojeda FP (1990) Cephalic anatomy of the herbivorous fish Girella laevifrons (Osteichthyes: Kyphosidae): mechanical considerations of its trophic function. Rev Chil Hist Nat 63:247-260

Vial CI, Ojeda FP (1992) Comparative analysis of the head morphology of Pacific temperate kyphosid fishes: a morpho-functional approach to prey-capture mechanisms. Rev Chil Hist Nat 65:471-483

Wainwright PC, Day SW (2007) The forces exerted by aquatic suction feeders on their prey. $\mathrm{J}$ R Soc Interface 4:553-560

Walsh K, Gibb AC, Arena A, Pace C (2007) Intramandibular bending and an "umbrella-like" jaw protrusion mechanism in the kissing gourami. Integ Comp Biol 47:P2.56

Zaret TM, Rand AS (1971) Competition in tropical stream fishes: support for the competitive exclusion principle. Ecology 52:336-342

Zedler J (1980) Algal mat productivity: comparisons in a salt marsh. Estuaries 3:122-131 